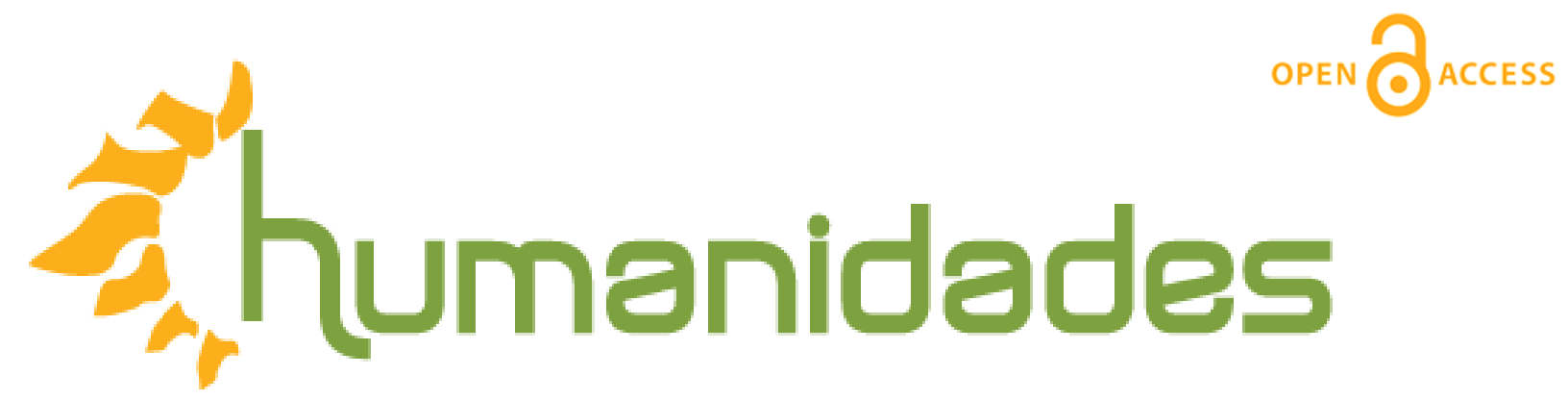

Revista de la Escuela de Estudios Generales, Universidad de Costa Rica

Julio-Diciembre, 2016 •Volumen 6, número 2 •EISSN 2215-3934•pp. 1-30

Recibido: 17-Noviembre-2015 Aceptado: 8-Marzo-2016

\title{
La palabra y el aire: Conjuros del alba de Jorge Chen-Sham
}

DOI: http://dx.doi.org/10.15517/h.v6i2.26744

\section{Carolina Sanabria}

Doctora en Comunicación Audiovisual y Publicidad. Profesora en la Escuela de Estudios Generales, Universidad de Costa Rica.

Correo electrónico: csanabriacr@yahoo.com

Todos los derechos reservados. Universidad de Costa Rica. Esta revista se encuentra licenciada con Creative Commons. Reconocimiento-NoComercial-SinObraDerivada 3.0 Costa Rica.

Correo electrónico: humanidades@ucr.ac.cr / Sitio web: http://revistas.ucr.ac.cr/index.php/humanidades 


\title{
La palabra y el aire: Conjuros del alba de Jorge Chen-Sham
}

\section{Resumen}

El presente artículo analiza el segundo poemario de Jorge Chen-Sham, Conjuros del alba, a la luz de la vinculación directa con el libro anterior, Nocturnos de mar inacabada. Destaca los elementos que guían la lectura de un trabajo muy estructurado porque la organización en ejes temáticos permite brindar una clave de lectura. En este caso la articulación está dada por la invocación de la palabra en su acepción divina como creadora de realidad bajo la forma de conjuros $-\mathrm{y}$ en sintonía estructural y lingüística con el discurso bíblico arcaizante, pero sin ceñirse por completo en virtud del carácter pagano de estos-. Pero los alcances de la palabra no se limitan a esta dimensión, puesto que el hablante lírico hace ver también su injerencia como mediador del deseo. Y si el poeta por principio lo que busca es la elevación de su espíritu, se mueve necesariamente en el ámbito del aire -que es el mismo elemento al que pertenece el alba-, donde las cosmogonías ubican el origen del mundo.
Palabras clave: Creación, verso, poesía, espiritualismo, magia.

\section{The Word and the Air: Conjuros del alba by Jorge Chen-Sham}

\begin{abstract}
This text analyses the second collection of poems written by Jorge Chen-Sham, Conjuros del alba and its link to his first book of poems, Nocturnos de mar inacabada. This article emphasizes the elements that lead the reading of a piece of work that is well-structured since it is organized in topics, what brings about a clue to its reading. The articulacy is promoted by the invocation of the divine word, that in this case is a reality creator, under the disguised of spells--and also in linguistic and structural tune with the archaic biblical discourse. Nevertheless, it is not completely biblical since the poems end up to be pagan. But the magnitude of the word does not circumscribe to this dimension, since the liric speaker shows its intervention as s desire's mediator. And if by definition what the poet looks for is his spirit' elevation, it will necessarily move in The air's territory which is the same element to which dawns belongs to, and where cosmogony locates the Origen of the world.
\end{abstract}

Keywords: Creative writing, verse, poetry, spiritualism, magic. 
En el 2011, el escritor costarricense Jorge Chen-Sham publicó el poemario Nocturnos de mar inacabado, trabajo con la que marca el inicio de una madura y productiva obra poética. Tres años después, presenta Conjuros del alba. Si su primer trabajo había sido expresamente concebido a partir de la forma del nocturno -con la noche como tema en la literatura de amplísima tradición y connotaciones desde donde se desencadenaba la proliferación de los sentidos hacia la búsqueda de sensualidad y el deleite-, con el mar como unidad cósmica dominante y articuladora, en el siguiente hay otro panorama que de igual manera parte de uno de los mayores tópicos líricos de la literatura universal.

En efecto, en Conjuros del alba se opera un desplazamiento hacia otro elemento cosmológico igualmente de notable fuerza lírica, pero de carácter más efímero y fugitivo -el alba, que da cuenta del paso inmediato de la transición de la oscuridad de la noche a la luz- y presente en la historia de las culturas y las religiones desde la base de los valores genésicos o fundacionales. Son ambos, pues, poemarios que se complementan: del mismo modo que el mar de los nocturnos que funcionaba como un indicador espacial, el alba apunta a un barrunto temporal. Aquí da cuenta del inicio por antonomasia, la primera blancura del día en oposición a la oscuridad de los nocturnos, lo que propone un puente de transición entre ambos escritos, como sugiriendo una continuidad directa. Así pues, 
mientras Nocturnos de mar inacabado trataba la pasión propia de la noche que conducía al despertar de los sentidos relacionados con la sensualidad (Sanabria, 2014) y de las significaciones sensoriales que se engendran en la nocturnidad, aquí se recurre al alba en relación con un estado de pureza espiritual; una visión del porvenir. El poemario, entonces, plantea un acontecimiento que está por llegar, ubicado en ese comienzo del día, el cual presenta la primera luz antes de que salga el sol, en otras palabras, de lo que no está entrado en la materia, sino que implica una realidad potencial, de tipo intangible.

Una constante en la lírica de Jorge Chen-Sham es su carácter innovador, en tanto articula la estructuración de su libro a partir de ejes que carecen de precedentes directos en el medio de la poesía costarricense. A pesar de que su obra poética se encuentra en fase de despunte, los dos textos surgen más que de imágenes fragmentadas o dispersas, de lo que Gómez-Redondo identifica como una calculada estructura preconcebida como un conjunto poético unitario (1994). En Nocturnos de mar inacabado la estética, la temática erótica y autorreflexiva del nocturno se separa de la práctica lírica imperante en el medio (Herrera-Ávila 2012). Lo mismo tiene lugar en Conjuros del alba, donde se parte de una ausencia en el medio en torno a una producción lírica, la de una estructura específica que está lejos del ejercicio propiamente literario, en la medida en que en principio se encuentra más próxima a la magia, ${ }^{1}$ al sortilegio, al 
hechizo y a lo inexplicado. Se encuentra más bien la vinculación a una construcción ritual de una acción, de cierto tipo de practicidad (Díez-Borque 1984). El consenso es que los conjuros se enuncian en rimas y versos y se forman con palabras o frases mágicas, pero adquieren más fuerza cuando se usan términos en latín o griego, lo que explica modos expresos como latinismos usados en el texto, por ejemplo, fiat lux, de profundis y vade retro.

Si los conjuros están sujetos, como lo define el Diccionario de la Lengua Española, a una fórmula establecida por la liturgia o el culto -de donde se deduce su formalización en orden y estilo implícito-, no dejan de compartir las posibilidades mágicas que posee la palabra. Precisamente una de las acepciones del conjuro, según la misma fuente, es la de "fórmula mágica que se dice, recita o escribe para conseguir algo que se desea". De este modo, aluden a la acción de conjurar, que a su vez remite a lo dicho de quien tiene potestad para ello, de pronunciar exorcismos. En este caso, quien los enuncia es la voz lírica, la cual se propone como vicario o sacerdote, con lo que el poeta vendría a constituirse en una suerte de intermediario secularizado. Lo que esta voz narrativa pone en escena, entonces, es el dinamismo aéreo del soplo suave (Bachelard, 1994) que insufla vida al universo, ${ }^{2}$ que hace las veces de un enviado divino. Esta fuente de enunciación se desplaza desde lo que por tradición ha 
venido a corresponder al poeta/vate hacia el mismo medio celeste: por eso no son conjuros al alba, sino del alba.

Es bien sabido que los textos mágicos se erigen en un elemento indispensable en la formación del ritual mágico. Desde tiempos inmemoriales, los magos los han usado para invocar y formular sus peticiones a fuerzas ocultas y sobrenaturales, como sostiene Campos-Moreno:

Hechiceras, adivinadores, curanderos, adivinas y, en general, personas supersticiosas, recitaron y transmitieron oraciones, ensalmos y conjuros mágicos. El uso que se le dio a estos textos es muy diverso: se emplearon como amuletos para protegerse de enemigos, para adivinar el porvenir, para curar enfermedades, como hechizos para enamorar, para provocar el regreso del hombre ausente... (2001, p. 70).

Estas creencias mágicas que se enuncian bajo la forma de conjuros, ensalmos y algunas oraciones no dejan al mismo tiempo de inscribirse bajo cierto tipo de marginalidad poética del Barroco. En efecto, si bien se construyen como una manifestación lírica, carecen de vocación de literariedad en vista de su carácter pragmático (Díez-Borque, 1984). En cierto modo, con su publicación, ChenSham trata de incorporar ese sentido marginal de la poesía oral y en 
la reconversión de la escritura replantea la estructura (rítmica, anafórica y contrastada) y del contenido (la retórica pragmática) que caracterizan a estas expresiones.

Sin embargo la acepción no incluye, desde luego, únicamente al sujeto que enuncia. En latín, 'conjuro' se corresponde con el verbo conjurare que a su vez remite al acto de conspirar. Se está, así pues, ante la evidenciación de una presencia doble: la del hablante lírico y la del lector. Aunque más que axioma, el lector es básico en el acto de poesía en tanto acto comunicativo, en la medida en que permite recrear un instante, aquí cargado de evocaciones mágicas, de una instancia etérea que cumple la función poética, pues más que transmitir, induce la experiencia de mundo (Núñez-Ramos 1998). No en vano otra de las acepciones de conjuro se relaciona con la lucha -recuérdese la conjuración de Catilina-; al lector se le incorpora al situarlo no solo en el vértice de la recepción, sino como cómplice de las tensiones e intimidades del yo lírico. Todo ello implica una situación en la cual el pacto implícito de la lectura cobra el sentido al coincidir en un mismo juramento y, en cierto modo, en un complot que concierne también a las fuerzas del universo, en última instancia, al alba.

Así las cosas, recurre a variados recursos estilísticos, como en el mencionado sentido de integrar al lector en solidaridad con su causa, 
en una especie de pacto implícito ya iniciado desde la lectura misma del texto. Así lo evidencia, por ejemplo, cuando el hablante lírico la emprende contra los malos amigos o los malos vecinos, e incluso, contra las mismas palabras -las de falso o mejor, como el mismo hablante lírico llama, de "vacuo esplendor"- que prorrumpen en la claridad del alba, las cuales ensucian la pureza del aire. El mecanismo parte de ese esquema básico de contraste que habrá de atravesar el texto de Chen-Sham en el planteamiento de esa realidad oscura, farragosa, a la que ofrece en cambio una esperanza o nueva posibilidad para plantearla positivamente, desde un inicio limpio de contaminaciones anteriores. ${ }^{3}$

Así pues, el poemario está estructurado en dos partes: la primera, titulada "Al alba de todas las cosas, la palabra", la cual remite al aforismo de la conocida tradición bíblica de que en principio era la

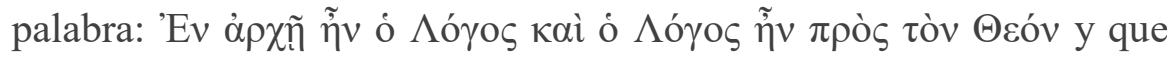
corresponde al latín In principio erat Verbum et Verbum erat apud Deum, esto es, que al inicio de todas las cosas estaba la palabra, la cual estaba con Dios. El alba, que también aparece en el título, es un elemento relacionado directamente con la magnitud celeste que las religiones ubican en lo alto: "una dimensión inaccesible al hombre" que "pertenece por derecho a las fuerzas y a los seres sobrehumanos" (Eliade, 1979, p. 58). Ya se sabe que la plegaria más popular se dirige al padre nuestro que está en los cielos, y es en esa instancia insondable 
donde diariamente se forma el alba, de rico simbolismo de trascendencia. De ahí se sigue que todas las cosas tienen un inicio a través de la palabra. Por eso la función del poeta en el sentido de crear se produce específicamente a partir del sentido de nombrar.

Desde esta óptica, del primero de los conjuros, "Las tareas del poeta", se esperaría un recuento o pormenorización, como indica el título, de las faenas que le atañen, pero este termina resultando engañoso, porque el texto no se centra en ellas ni siquiera mínimamente. Cada una de las estrofas gira alrededor de las calidades del vate, el cual es definido siempre al inicio como "incansable", "insondable", "invencible" e "insaciable". Si bien se trata de adjetivos que no determinan o precisan, sino que aumentan la nebulosa en torno a su figura, permiten establecer "el proceso mismo de la creación por el cual tiene que pasar cualquier poeta" (Vallejos-Ramírez, 2014, p. 5).

Solo en algunos versos el hablante lírico se permite volcarse sobre algunas fuentes de naturaleza oscura, de las que emanan fuerzas negativas que cobran personalización (en los enfants tordus, las circes plañideras y los incómodos vecinos) o no necesariamente (como los efectos de las crisis del mundo posmoderno y los que someten los deseos a pactos fiscales). Estas unidades enumerativas propias de la técnica acumulativa, nominal, adjetival y caótica (Díez-Borque, 1985) se enuncian desde la oración cristiana del exorcismo, en una suerte de 
vade retro, hasta adquirir la fuerza tal de titular uno de los poemas. Se trata de una forma de referirse a esos sujetos, objeto profundo de su desprecio, como un modo de devolverles su propiedad engañosa, esto es, como una suerte de protección del hablante a partir del enunciado mágico del rechazo, pero sin dejarse invadir de esos malos deseos que los-otros proyectan. Así pues, está contenida una separación de esas nociones de carácter maligno con respecto a un yo lírico que se inviste del poder mágico dado por la palabra que las exorciza y convierte el conjuro en arte. Por tanto, los conjuros se desempeñan como ese tipo de no acontecimiento constructivo que sostiene Terry Eagleton: "Evitando una intervención directa en los asuntos humanos, puede permitir que la verdad y la belleza acontezcan, en formas que entonces pueden lograr que las cosas ocurran" (2010, p. 111), donde se revela la fuerza, el poder y el esplendor de la palabra.

Concretamente, así se aprecia en "Invocación (paráfrasis del salmo)" donde la voz enunciadora ruega protección de todos los peligros. A ese respecto, Vallejos-Ramírez considera que estas invocaciones funcionan "más como ensalmos porque llevan implícito un planteamiento moral y de justicia divina... [...] como un rezo de tipo mágico-religioso con mayor carácter esotérico y que envuelve un proceso de sanación" (2014, p. 3). Para ello el hablante lírico recurre a una fórmula típicamente usada en el discurso litúrgico que a grandes rasgos responde a los salmos de súplica donde priva el ruego personal 
ante el colectivo, pero enunciado en calidad de rey o sacerdote, en última instancia mediador. Aquí esa instancia parte de una estructura interesante, articulada en un primer momento por la anáfora como esquema de reiteración que marca el ritmo, esencial en la poesía (Moreiro, 1996) y también en construcciones de carácter religioso. Ese primer momento es un largo y problemático paréntesis que no cumple la estricta función de interrumpir, porque no interrumpe nada: aparece al inicio y tampoco puede tomarse como prescindible porque es el más extenso de todos los versos. Además, se condensa el elemento básico del texto que subyace a todas las cosas: la presencia divina, como el aire, en todas partes. El uso particular de la estrofa permite apreciar aquí la función como estructura de pensamiento poético en tanto "distribuye las emociones, las ideas, los pre-juicios y los sentimientos del poeta conforme a nuevos esquemas lógicos" (Gómez-Redondo, 1994, p. 99). Una vez que acaba este largo verso entre paréntesis, una nueva estrofa abre de la siguiente manera:

El silencio conspira para que el creyente se vuelva hacia el salmo y pida el portento que dignifica (Chen-Sham, 2014, p. 41).

Ese silencio que el hablante invoca, tan caro a las religiones, da pie para que de inmediato aparezca una línea punteada, por cierto 
recurso constante del poemario como forma divisoria de la siguiente estrofa final, la cual mantiene la misma estructura anafórica en virtud de la reiteración de la preposición 'en' de ese primer verso para subrayar el alcance o la extensión del poder del Señor de la Luz: en las ferias del amanecer, en las asperezas del ojo, en las memorias alambradas.

Como sostiene Díez-Borque, la ponderación, calificación y valoración, son frecuentes en las invocaciones a través de la función de captatio benevolentiae, en la medida en que el hablante lírico admite la necesidad de la mediación en los destinatarios de las invocaciones con el propósito de conseguir unos fines deseados (1985), lo que explica su carácter pragmático. De igual modo, los epígrafes y la composición misma evidencian que el poemario excede un sentido propiamente místico, como se muestra en las resonancias a la tradición lírica latina y española que cita, elabora y amplía - estrategia que por cierto el autor mismo hacía ostentación en su poemario anterior- ${ }^{4}$

Precisamente hay estrategias que no son solo las atribuibles a la tradición barroca del conjuro, por cuanto apuntan a reforzar el sentido del mensaje expresado, y que van más allá de la construcción retórica porque incorporan el factor tipográfico. En "En la noche de todos los ruidos" el texto da la impresión de estar compuesto por tres 
estrofas en una misma página, pero tras haber dado por finalizada la lectura, el lector se encuentra con un efecto de sorpresa, porque se percata de que el texto poético no ha terminado y continúa en el reverso, de forma tal vez semejante al mismo martirio cotidiano del martilleo inacabable que expresa el hablante lírico en el poema.

En cualquier caso, el conjuro está abocado a lo mismo del resto, esto es, a la liberación de un agente nocivo que coincide con una pragmática cristiana que evita responder de la misma manera, lo que evita la identificación con el sujeto oprobioso, para lo cual le envía los mejores deseos, que contrastan con las acciones perniciosas de aquel. Entonces, si el conjuro a través de la palabra permite la separación del enunciador con respecto al otro es porque crea la conciencia de su libertad, la cual necesita el espacio para moverse, es al aire donde se lanza.

De hecho hay una presencia innegable del intertexto bíblico desde la forma de construcción, al esbozar los deseos y la presencia de una fuerza superior en la estructura de los explicitados salmos. De igual modo, también se hace evidente en construcciones sintácticas reconocibles del rito católico, entre ellas las invocaciones a la fuerza divina bajo estructuras lingüísticas codificadas de petición (“Líbranos") y, en el mismo poema ("Líbranos del tóxico amor"). Asimismo, la expresión del deseo que prive la voluntad suprema 
("Hágase"), así como la recurrencia conceptual del perdón ("Perdona"): todas estas formas aluden a una experiencia -más que propiamente cristiana- mística. Al mismo tiempo, son estructuras que constituyen, ampliamente, del formulismo repetitivo; es decir, que figuras retóricas como la repetición, el paralelismo, la rima no asociada a valores estróficos entre otros, constituyen la parte privilegiada de los recursos de formalización de los conjuros (Díez-Borque, 1985).

Aunque la estructuración del texto de Chen-Sham parezca reproducir el discurso cristiano, no funciona exactamente así: téngase en cuenta que no se trata de rezos, sino de conjuros. Pese a asumir la estructura del discurso cristiano, los conjuros están dotados de una indefinida connotación pagana. Hay así una sutil distancia, propia de la actividad lúdica literaria, como el recurso de parodia y negación con que cierra "Parcours du combattant": "¡Ven sueño reparador!/ ¡Hágase en mí tu ingrata voluntad!” [cursivas añadidas] (ChenSham, 2014, p. 40). El conjuro, por tanto, es una construcción lingüística básicamente ambivalente.

Algo parecido sucede en "Ante las crisis de este mundo posmoderno", donde la enunciación empieza desde una forma de petición que comúnmente se suele atribuir al lenguaje arcaizante bíblico (de acuerdo con la variedad del español americano) en un 
distanciamiento resaltado por el entrecomillado "Perdonad a los que os ofenden" [cursivas añadidas]. Sin embargo, de inmediato pasa a cuestionarse:

Pero, ¿cuándo?, ¿sin arrepentimiento?, ¿sin dar nada a cambio?

Entonces de inmediato aparece un cambio de la segunda persona en plural propia del discurso bíblico formular y arcaizante -vosotros- a la exhortación en el modo de registro normal de esta variedad lingüística:

El mundo es de ustedes" [cursivas añadidas] (Chen-Sham, 2014, p. 47).

La idea bíblica se refuerza con la atmósfera tal y como se aprecia en el poema titulado "Conjuro de diciembre ventoso" desde su respectiva estación y el mismo componente etéreo del alba, el viento. Con su naturaleza ambivalente, la cual es "dulzura y violencia, pureza y delirio" (Bachelard, 1994, p. 287), el viento construye un clima también emocional que alude a la presencia del soplo divino como el Espíritu Santo, que es invisible pero perceptible. 
Igual de perceptibles son los pases mágicos, estrategia común en el ritual pagano y litúrgico, al que es remitido en "Conjuro con los dedos modulantes", en confusión con los sonidos y el eco de la música, la cual parece estar dirigida por dedos que se mueven de forma mágica. Precisamente con ello se tiene otra de las posibilidades que ofrece este poemario en la concepción de conjuros antes que poemas: en la significación de parquedad ante esos momentos de arrobamiento o experiencias místicas, que las palabras no alcanzan para describirlas puesto que implican una superación de la razón, de lo humano o de la mente superior, como expresa el hablante lírico de "Para contrarrestar el vacuo esplendor de algunas palabras" en los primeros versos de los dos primeros cuartetos:

El vacío se cincela con la voz, se conjura si se sabe inventar olvidos. No se trata de rescatar de la ausencia, $\mathrm{Ni}$ de infundir sentido a las cosas.

La voz se moldea con los silencios, se disuelve a duras penas sin efectos. Debe romperse el letargo de las cifras, bajo la sospecha de la herida abierta (Chen-Sham, 2014, p. 43). 
El vacío, el silencio y la ausencia, lo mismo que el alba, son equivalentes a la amplitud, al espacio, al aire. En 1943 Bachelard escribió que en la poesía no importan solo las imágenes visuales ni lo que estas evocan, sino el silencio que prevalece tras el verso. El hablante lírico parece compartir esta idea en las marcaciones en el texto bajo la disposición de pausas, de líneas punteadas para sugerir un silencio que aflora desde sus raíces hundidas en el sueño (1994).

Pero estos componentes etéreos e intangibles tienen un carácter únicamente solemne y formal. Con el aire se relaciona también un objeto de carácter pagano y lúdico propio de los conjuros con el que contrasta. Se trata de un texto asociado con el ocio, con la distracción y el recreo: el papalote. Así, el "Conjuro del papalote" viene a desmitificar el tono ceremonioso y si se quiere grave de los poemas de la primera parte, pero también a incorporar el elemento del juego que, como ya se dijo, a veces caracteriza la fórmula de los conjuros. ${ }^{5}$

A pesar de tratarse de un objeto de carácter por definición lúdico, "Conjuro del papalote", que cierra la primera parte, no deja de estar vinculado a lo que inextricablemente está ligado a la metáfora axiomática de las alturas, a la elevación, y en ocasiones apuntado en algunos textos de la primera parte (en el mencionado "diciembre ventoso", "levántense", "si me refugio en las alturas"). Se trata de una idea consonante, como afirma Bachelard, con la operación 
dominante de la vida espiritual propia de la actividad del poeta, que quiere crecer, elevarse, que busca instintivamente la altura (1994). Además también posiciona su actividad soñadora y sus valores de elevación (la luz, el reposo, la paz) en la verticalidad, en la sima: no es casual que paisajistas como el romántico Caspar David Friedrich hubieran alcanzado la perfección de sus paisajes -de cúspides de montañas o cimas rocosas- alegóricos de la sensación visual de lo sublime. Algunos de sus más famosos cuadros logran tal efecto encumbrando el encuadre, a veces desde un personaje arrobado e insignificante ante la inmensidad de lo abierto. Se trata de puntos donde el aire es más puro, y no por nada apuntaba Cirlot que en las cosmogonías elementales se ha generalizado la creencia en el aire como origen de todas las cosas (1992). El mencionado conjuro, además, viene precedido por "En el alba", donde el hablante lírico daba cuenta de su llegada, de escabroso camino, a un punto indefinido -si bien de "peso breve"- contrastante con la contundencia de su presencia. El poema está construido desde la condición etérea e inmaterial de un hablante lírico que, una vez más habría de corresponderse, fundirse con una entidad abstracta, el alba.

Tampoco cabe olvidar que la palabra está vinculada al deseo, que es el punto de partida de la teoría psicoanalítica en la explicación de textos literarios. De ahí que la segunda parte, "Y entre todas las palabras, el deseo", el hablante lírico vuelva al tema del amor pero 
expresado como deseo antes que realización, lo que marca cierta consonancia temática y enlaza continuidad con Nocturnos de mar inacabado. En términos muy generales esta sección incorpora poemas de un tono más sensorial que los de la primera parte. Por lo demás, algunos como "Soy marinero" o "En los marinos devaneos del deseo" retoman sobre el tema marítimo al menos en el título ${ }^{6}$. La incertidumbre atribuida a la vacilación de las aguas puede funcionar como metáfora del estado anímico que implica una consonancia con la idea de hacerse a la mar o embarcarse, con el vaivén emocional, sensorial de su fuente de enunciación:

Marinero quiero ser

y en tu cuerpo

me embarco para no encallar.

Fuera de mis límites,

cercado en tu inmensidad

me abandono (Chen-Sham, 2014, p. 75).

Así se resuelve su ambigüedad mítica de sentidos entre la vida y la muerte de forma tal que parece decantarse por la primera, en su carga de positividad y tono de luminosidad. Y para que no se olvide que se trata de un conjuro, el hablante lírico lo señala, como sin pretenderlo, entre paréntesis, en dos ocasiones: una vez comenzado, después de la segunda estrofa: "(Conjuro al que puede oírme/ y no se resiste)" 
(Chen-Sham, 2014, p. 75) y una vez más al final: "(Conjuro a quien se resista/ al consuelo exacto/ del agua perenne") (Chen-Sham, 2014, p. 76).

Los títulos, en efecto, son un buen indicador de ese cambio de sección o esquema contraste propio de la poesía y también de los conjuros, puesto que pasa de la negatividad oscilante de la palabra que ilumina la oscuridad, al alba que precede. Una vez más hay una clara remisión a Nocturnos de mar inacabado en lo que concretamente Tatiana Herrera-Ávila había visto como un contraste bicromático (2012) -propio del movimiento barroco tanto en la literatura como en la plástica (la composición de claroscuro en Velázquez, Rembrandt, Caravaggio)- que estructura también Conjuros del alba. De igual modo, "De los cuerpos entrelazados" sugiere un movimiento o paso similar, el envolvente de los amantes que ofrecía del poemario anterior "Retroalimentación del gozo pleno", únicamente que aquí conjura una presencia adicional: el buen Dios y su voluntad mediadora en la realización del amor a través de la petición.

En cierto modo puede decirse que este conjunto de textos componen una reiteración de temas sensoriales como los cuerpos, las caricias, los besos, ya presentes en el poemario anterior. La diferencia clave reside en que su enfoque no se enmarca tanto en el ámbito de la realización sino desde la retórica de la petición a través de la palabra 
mágica, esto es, del conjuro, del que ha dicho Barthes que tampoco deja de ser generalizada la práctica de consultas mágicas, pequeños ritos secretos y acciones votivas enfiladas a la vida amorosa (1996). De ahí que en general el énfasis en esta segunda parte se desplaza de la palabra, dominante en la primera, al deseo. Si bien, como acaba de decirse, los poemas de esta sección son de otro espíritu -más animado, más positivo-, no están ausentes los que operan como exorcismos, como es el caso de "Contra los proyectos de conjuro", donde el lenguaje se usa contra el lenguaje mismo -el vacuo esplendor de las palabras de la primera parte-. El hechizo de la palabra sirve para invocar no solo el componente destructivo en el plano personal y más ampliamente, social (dirigido a los "calculadores de religión,/ evasores políticos,/ corruptores de engordes", incluso también a las recientes y globales políticas de recortes dirigidas por las dictaduras, los gobiernos y la lógica de los mercados por igual) lográndose colar cierto matiz combativo, de insatisfacción -no únicamente la del amor, que priva por encima de todo-. Pero para eso debe someterse de igual modo a la retórica del conjuro, para que la demanda surta efecto.

Parece que aquí cobran más importancia los besos, que son el instrumento de los labios que se imprimen sobre el cuerpo que para la palabra, en última instancia el conjuro, tenga efecto -lo que remite de nuevo al carácter pragmático-- Al igual que la palabra funge 
como intermediario entre el objeto y el que lo percibe, el deseo viene a hacer lo propio entre los amantes en la concreción del amor que, a diferencia de Nocturnos de mar inacabado, no se lleva a cabo. Aún. Por eso es un deseo no realizado -que a eso responde el acto del conjuro-, un deseo en suspensión, en el aire.

A través del conjuro, por ejemplo, en "Líbranos del tóxico del amor", se lleva a cabo la preparación de las condiciones anímicas, la situación previa al despliegue amoroso, que en general se continúa en esta sección. No es un amor concreto como el del poemario anterior, enunciado desde la sensualidad y que incluso incorpora una sexualidad más explícita, sino que aquí se trata de una pasión diferida. No es un amor que se da en el acto, como expresión del acto, sino como deseo, como esperanza de conseguir algo que no se tiene. De igual forma es llamativo que Chen-Sham utiliza de nuevo esta estructura lingüística del discurso bíblico arcaizante -en este caso tomado de Mateo 6:13: "Y no nos metas en tentación, mas líbranos del mal. Porque tuyo es el reino y el poder y la gloria para siempre jamás"-, para estructurar los dos últimos versos de equivalente manera:

Líbranos del tóxico amor de las conjeturas, porque es el preámbulo de futuros convites [cursivas añadidas] (Chen-Sham, 2014, p. 61). 
El amor, pues, se mantiene en el ámbito irrealizado del deseo, se conserva y de ahí se invoca a la eternidad, que se accede a través de los conjuros. Precisamente a eso responden: para que los deseos tengan que ser verbalizados a fin de llevarse a cabo. Desde ese marco se ofrece, en remisión a la antigüedad clásica del subgénero lírico griego, el "Epitalamio de cada día", que celebra los esponsales de boda. Pero de nuevo da pie a la ambigüedad, porque el vocativo del amado se confunde exprofeso en la penúltima estrofa con el sueño que retoma a su vez el conjuro de "Parcours du combattant" de la primera parte, la cual giraba en torno a la preparación del sueño -en plena noche solitaria, hablando de "las delicias del dormir quedito", sobre el "don de acostarse" que da paso al "dichoso sueño" hasta culminar con los mismos versos del llamamiento al sueño: "ven sueño reparador"-. Por eso la constante apelación al sueño a lo largo de todo el texto resulta tan persistente, porque tiene que ver también con el concepto del sueño del vuelo que se encuentra a la base del psiquismo y que por la especificidad de su sustancia está sometido a la ingravidez, a la levedad. No obstante, lejos de mantenerse en esa dimensión, es una experiencia onírica que deja huellas profundas -como estas, en forma de conjuros- en la vida despierta (Bachelard, 1994).

Desde esta línea, hacia el final del poemario, "El golpe de gracia", ofrece un cierre luminoso que recuerda al receptor el efecto 
pragmático de los conjuros por el poder de los deseos, que pueden cumplirse. Se cumple así en el entendido de que siempre y cuando se enuncien o verbalicen de manera adecuada, presumiblemente según se ha dicho, como conjuros, es decir, desde una estructura que se repite en todo el poemario y que semeja a las letanías. La única diferencia reside en que aquí no se organiza o enlistan las divinidades mediadoras, sino la enumeración corresponde a los alcances del poder y la palabra.

Y por último, el epílogo es un insospechado e inesperado -por cuanto procede de otra tradición cultural de expresión- haikú:

El Cielo conjura a la Tierra, se abrazan con estupor... (Chen-Sham, 2014, p. 88).

Por la brevedad de su estructura no chirría con la de los conjuros y retoma la idea de la armonía del cielo y de la tierra, una especie de síntesis que no solo abarca los dos unidades míticas motivo de culto en cosmogonías a lo largo de la faz de la tierra y de la historia, sino que se articulan ambos poemarios también: el mar (en la tierra) del anterior y el alba, el aire del presente. 
En este segundo poemario de Chen-Sham, el eje articulador viene inequívocamente dado por la palabra. Pero no una palabra cualquiera, sino una que se enuncia como conjuro en la estructuración de su forma: con sus repeticiones a la manera codificada de letanías, epitalamios, peticiones, salmos a la divinidad, expresiones vade retro o exorcismos, acompañamiento de gestos (dedos modulantes o exagerados, prestidigitaciones) en un ritual que está pensado para el comienzo del día (el alba), de claridad y pureza en el ambiente. Y la luz, el vuelo, la ligereza que se mencionan en el texto son elementos que entran en conexión directa con el aire (Cirlot, 1992): de ahí que estos conjuros se estructuren como imágenes mayormente inmateriales, etéreas, pertenecientes a la dimensión de los sueños y de la ensoñación. Ello hace que el poemario resulte de un tono más místico y específicamente abstracto, en claro contraste con el anterior Nocturnos de mar inacabado, donde la fuerza trascendente derivaba de la puesta de los sentidos. Es así como entonces, a diferencia de la vista, que direccionaba el poemario anterior y que se ha caracterizado por ser esencialmente un sentido no dinámico -por cuanto se fija en la imagen, por cuanto se detiene en las texturas de lo concreto y se regodea en ellas-, la palabra se encuentra más cercana a la imaginación, y su dominio, en sintonía con Bachelard, pertenece al aire. En última instancia, a los fenómenos volátiles supeditados con las operaciones de sublimación -de las cosas- y de ascensión -del 
espíritu- (1994), que es también el lugar -el no-lugar, el vacíodonde esencialmente se mueve la actividad del poeta. 
Bachelard, G. (1994). El aire y los sueños. Ensayos sobre la Referencias imaginación del movimiento. México: Fondo de Cultura Económica.

Barthes, R. (1996). Fragmentos de un discurso amoroso. México: Siglo XXI.

Campos-Moreno, A. (2001). "El ritmo de las oraciones, ensalmos y conjuros mágicos novohispánicos". Revista de literaturas populares, 1, 1:69-93.

Chen-Sham, J. (2011). Nocturnos de mar inacabado. San José, Costa Rica: Interartes.

Chen-Sham, J. (2014). Conjuros del alba. San José, Costa Rica: Editorial de la Universidad de Costa Rica.

Chevalier, J. (ed) (1986). Diccionario de los símbolos. Barcelona: Herder.

Cirlot, J-E. (1992). Diccionario de símbolos. Barcelona: Labor.

Díez-Borque, J. M. (1985). "Conjuros, oraciones, ensalmos...: formas marginales de poesía oral en los Siglos de Oro”. Bulletin Hispanique, 87, 1-2: 47-87.

Eagleton, T. (2010). Cómo leer un poema. Madrid: Akal. 
Gómez-Redondo, F. (1994). El lenguaje literario. Teoría y práctica. Madrid: EDAF.

Herrera-Ávila, T. (2012). "Nocturnos de mar inacabado o de la incompletud en el discurso del Eros". Revista de Filología y Lingüística, XXXVIII (2): 45-50.

Moreiro, J. (1996). Cómo leer textos literarios. El equipaje del lector. Madrid: EDAF.

Núñez-Ramos, R. (1998). La poesía. Madrid: Síntesis.

Eliade, M. (1979). Tratado de historia de las religiones. México: Era.

Sanabria, C. (2012). "La preeminencia de la forma en la poesía de Jorge Chen Sham", Káñina, Revista de Artes y Letras de la Universidad de Costa Rica, XXXVI (1): 35-41.

Vallejos-Ramírez, M. (2014). "El ensalmo y otros rituales mágicos en Conjuros del alba (Estudio introductorio)". Chen Sham, J. Conjuros del alba. San José, Costa Rica: Editorial de la Universidad de Costa Rica. 
1. Del tipo abracadabra, cuya etimología (sin consenso entre Notas arameo y hebreo) involucra los conceptos de crear y hablar.

2. Que se asocia directamente con el aire, elemento del cual es posible, para Cirlot, identificar tres factores: "el hálito vital, creador $\mathrm{y}$, en consecuencia la palabra; el viento de la tempestad, ligado en muchas mitologías a la idea de la creación; finalmente al espacio como ámbito de movimiento y de producción de procesos vitales" $(199$, p. 60).

3. Es así como se explica que uno de los conjuros, "En la noche de todos los ruidos" - donde ha definido a sus molestos vecinos a partir de la indolencia y la envidia, de los incansables saboteos del sueño y plantee que su única defensa, su única réplica está en su palabra-, cierra inesperadamente con bendiciones.

4. Como se cuela en los sentimientos básicos del odio y amo del poema 85 de Catulo -al que el autor remite de manera explícita al inicio de los versos de "Para el pretendido olvido de los que pulverizan los resquicios de la amistad"-, por no mencionar los abundantes epígrafes extraídos de la literatura universal. 
5. Que refuerza el juego con la palabra en sí misma propia de la ritualización lingüística del conjuro (Díez-Borque, 1985).

6. Es como si el hablante lírico pareciera decantarse por la incertidumbre tradicionalmente asociada al mar -en su simbolismo de la dinámica de la vida para Chevalier: "todo sale del mar y todo vuelve a él: lugar de los nacimientos, de las transformaciones y los renacimientos" (1986, p. 869)-.

*Se respetan las correcciones filológicas y de estilo realizadas por la autora.

\section{¿Cómo citar este artículo?}

Sanabria, C. (Julio-diciembre, 2016). La palabra y el aire: Conjuros del alba de Jorge Chen-Sham. Revista humanidades, 6(2), 1-30. Recuperado de http://www.revistas.ucr.ac.cr/index.php/humanidades/article/view/26744 